\title{
Recurring cardiac myxoma
}

\author{
IAN R GRAY, W G WILLIAMS \\ From the Walsgrave Hospital, Coventry, West Midlands
}

SUMMARY Of a series of 14 patients surviving operation for atrial myxoma, two developed signs of recurrence of the tumour. In both cases the patients underwent two further separate operations for recurrent lesions. The time before the second recurrence was nearly 11 years and four and a half years. In neither case did histological examination show malignant change.

These two cases of recurrent atrial myxoma, together with four other reported cases, indicate that a second recurrence may occur in about $25 \%$ of patients with a first recurrence. Multiple foci of tumour growth is probably the explanation for recurrence in most cases.

Myxoma is the only primary tumour of the heart to occur with any frequency. It arises from the endocardium, usually of the atrial septum, and grows into the left or right atrial cavity. Seventy five per cent of myxomas are in the left atrium, $20 \%$ in the right atrium, and the remainder in one or other ventricle. It began to be recognised in life in patients undergoing mitral valvotomy and could be visualised by angiocardiography. Echocardiography has greatly improved the promptness and the accuracy of clinical diagnosis. Crafoord in 1954 was the first to remove successfully a left atrial myxoma. ${ }^{1}$ With open heart techniques surgical treatment has become safe and effective.

It was in 1967, several years after surgical treatment became widely practised, that Gerbode et al encountered the first recurrence. ${ }^{2}$ They thought it occurred because the tumour had not been completely removed at the first operation and recommended wide resection of the atrial septum around the point of origin of the tumour. Read et al reported, however, a patient with recurrence after a myxoma had been removed with excision of the septum around its origin. ${ }^{3}$ The recurrent tumour arose from the atrial wall, not the site of the original myxoma. Jugdutt $e t$ al stressed that five of the nine recurrences then recorded in published reports had happened despite wide resection and patching of the atrial septum. ${ }^{4}$ Their patient had a recurrence two and a half years after the original myxoma was excised. When he died four years later there

Requests for reprints to Dr Ian R Gray, Cardiology Department, Walsgrave Hospital, Clifford Bridge Road, Coventry CV2 2DX, West Midlands.

Accepted for publication 29 January 1985 were no less than six myxomas in the left atrium, one of which extended through the septum to the right atrium. There are three other reports of myxoma recurring for a second time. ${ }^{356}$ In one of them, O'Neil et al reported a patient who developed a recurrent myxoma on the annulus of the tricuspid valve four years after a left atrial myxoma was removed and a further recurrence in the right atrium eight years later. ${ }^{5}$ They emphasise that each recurrence was "upstream" from the one before and unlikely, therefore, to be caused by seeding from an earlier lesion.

Cleveland et al reported a patient who had a myxoma removed from the posterior wall of the left atrium. ${ }^{6}$ It recurred at the same point on the atrial wall. A second recurrence took place when there was a tumour on the posterior wall of the atrium together with multiple smaller myxomas elsewhere in the left atrium. They described the cellular pattern of the tumour as "more aggressive" with each recurrence, the second recurrence being malignant.

We report two further cases of repeated recurrence of myxoma which we have encountered in a total experience of 15 patients with atrial myxoma, 14 of whom were operated on successfully.

\section{Patients and methods}

\section{CASE REPORTS}

\section{Case 1}

A 42 year old woman had suddenly developed severe pain in the left leg at the age of 18 years and was admitted to hospital for a few days in 1960. Six months later she again entered hospital with fatigue, breathlessness, and haemoptysis. There were presys- 
tolic and systolic murmurs at the mitral area, the chest radiograph showed pulmonary congestion, and she was profoundly anaemic. She was thought to have rheumatic carditis and responded to steroid treatment. She relapsed a few weeks later and again entered hospital, being admitted this time to a different ward. The ward sister remembered having looked after her sister two years earlier, when she died of a left atrial myxoma. This information resulted in a reappraisal of her condition, when it was found that there were no arterial pulses below the femoral arteries in either leg. Pulmonary angiography showed a filling defect in the left atrium. In May 1961, under surface cooling, the left atrium was opened and a large myxoma removed. No attempt was made to resect the atrial septum around its point of origin, which was in the region of the fossa ovalis. She made a good recovery apart from bilateral intermittent claudication, which gradually disappeared, and occasional paroxysmal tachycardia. She later had two uneventful pregnancies.

In October 1972, she developed pain and discoloration of the right forearm and hand followed by claudication in the arm. Again there were systolic and diastolic murmurs at the mitral area. Pulmonary angiography showed a filling defect in the left atrium. In April 1973, during exploration of the right atrium under cardiopulmonary bypass, a small myxoma was found, which arose from the fossa ovalis. After this had been widely excised a second large filamentous myxoma was removed from the left atrium. The origins on the atrial septum of the two tumours were quite separate from one another. They were both removed together with a cuff of normal septum from around their origins and the septum repaired with a patch of Teflon. The completeness of the excision was confirmed by examining blocks of tissue taken from the excised portions of the atrial septum. She again made a good recovery apart from occasional paroxysmal tachycardia.

Early in 1984 she became unwell with dyspnoea on moderate exertion and a sense of profound malaise. She was quite certain that the myxoma had recurred. There was a long systolic murmur at the left sternal edge and suspicious echoes in the neighbourhood of the tricuspid valve on $\mathbf{M}$ mode echocardiography. At cardiac catheterisation there was a pronounced diastolic gradient across the tricuspid valve. Right atrial angiocardiography showed a large lobulated filling defect closely related to the ventricular aspect of the tricuspid valve. At her third operation, in February 1984, we found an enormous myxoma which occupied most of the right ventricular cavity. It had multiple points of attachment to the papillary muscles, and to remove it completely the tricuspid valve had to be excised. There was a second small myxoma in the left atrium which arose from the endothelium covering the Teflon patch previously placed in the atrial septum. This also was removed. She developed atrial flutter a few days later which required DC cardioversion.

The histology of the tumours removed at all three operations was that of benign myxoma with no suggestion of malignant change.

\section{Case 2}

A 47 year old man had collapsed with loss of consciousness and slurred speech in 1961 when he was 23 years old. We found no cause for this attack. Two years later he developed a right hemiparesis and focal epilepsy. Left carotid and vertebral arteriograms in 1964 showed what were described as multiple angiomata in the left hemisphere, two previous carotid studies having been normal. At the time we believed this to be a primary vascular condition, but with hindsight the appearances closely resembled those subsequently reported in patients with cerebral embolus from left atrial myxoma. ${ }^{7^{-9}}$ In 1970, nine years after the first cerebral symptoms, he had a femoral embolus. Histology of the material removed at embolectomy showed the typical appearances of myxoma. There were no cardiac symptoms and no abnormal signs in the heart. Intracardiac pressures were normal, but pulmonary angiography showed a filling defect in the left atrium. In June 1970 a myxoma $5 \mathrm{~cm}$ in diameter was removed from the left atrium together with its pedicle and an area of septum around its base. We repaired the septum by direct suture. He developed atrial flutter afterwards which required $\mathrm{DC}$ cardioversion.

Fifteen months later he was taken ill with fever, breathlessness, slurred speech, and hyperaesthesia of the right side of the body. He had atrial fibrillation and pronounced pulmonary oedema. Pulmonary angiography showed a large filling defect in the left atrium. At operation in September 1971 we found a myxoma which arose from the atrial septum and which completely filled the left atrium. We removed the tumour together with the atrial septum around its point of origin, which was repaired with a patch of Teflon. Examination of blocks of the septal tissue confirmed that removal had been complete.

He remained well until December 1975 when he suddenly lost consciousness with Adams-Stokes syncope. There was second degree heart block with Wenkebach phenomenon, and the ventricular complex showed right bundle branch block with left posterior fascicular block. These conduction abnormalities resolved spontaneously. There were no abnormal signs on auscultation, and an $\mathbf{M}$ mode echocardiogram was normal. Angiocardiography showed a filling defect in the left atrium and another 
Table 1 Incidence of recurrence of atrial myxoma

\begin{tabular}{lcc}
\hline Authors & $\begin{array}{c}\text { No of cases } \\
\text { surviving operation }\end{array}$ & Recurrences \\
\hline Gerbode et al $(1967)^{2}$ & 7 & 1 \\
Croxson et al $(1977)^{11}$ & 9 & 0 \\
Kabbani and Cooley $(1973)^{12}$ & 17 & 1 \\
Chassignolle et al $(1973)^{13}$ & 10 & 1 \\
Puel et al $(1973)^{14}$ & 5 & 1 \\
Hardin et al $(1974)^{15}$ & 12 & 1 \\
Sasaki et al $(1977)^{16}$ & 9 & 1 \\
${\text { O'Neil et al }(1979)^{5}}_{\text {Donahoo et al }(1979)^{17}}$ & 5 & 1 \\
Bulkley and Hutchins $(1979)^{18}$ & 14 & 0 \\
Richardson et al $(1979)^{19}$ & 12 & 0 \\
Attar et al $(1980)^{20}$ & 11 & 0 \\
St John Sutton et al (1980)10 & 6 & 1 \\
Cleveland et al $(1983)^{6}$ & 39 & 2 \\
Marvasti et al $(1984)^{21}$ & 15 & 1 \\
Present series $(1985)$ & 9 & 0 \\
Total No (\%) & 14 & 2 \\
\hline
\end{tabular}

in the right ventricle. At a third operation in February 1976 , there was a large myxoma of the right atrium together with two small ones, a large myxoma of the right ventricle that affected the tricuspid valve, a myxoma in the left atrium which arose from endothelium covering the Teflon patch, and a further myxoma in the main pulmonary artery which extended into the left pulmonary artery. All six myxomas were removed; the tricuspid valve was replaced, and a permanent pacing system implanted. $\mathrm{He}$ remained well eight years later. The histology of the tumour tissue removed at the three operations showed only the appearances of benign myxoma.

\section{Discussion}

The largest series of patients with myxoma operated on in a single centre is that reported from the Mayo Clinic. ${ }^{10}$ Two out of 39 patients who survived operation had recurrence, an incidence of $5.4 \%$. This may be an underestimate as half of their patients had been followed for less than 10 years. When 16 series of cases of atrial myxoma are added together, totalling 194 patients who survived operation, there were 13 with recurrence, an incidence of $7 \%$ (Table 1 ).

We have found reports of 21 patients whose myxoma recurred after surgical treatment, to which we have added the present two cases above (Table 2). Their ages ranged from 5 to 59 years at the first operation. The sex was recorded in only 13 of the 23; nine of the 13 were male. This is surprising since primary myxoma occurs much more often in women than in men. The original myxoma was in the left atrium in every case, and in 14 the recurrence also was a single tumour in the left atrium. The recurrent tumour was in the right ventricle in one case, in another it involved the chordae and a cusp of the mitral valve, and in another it was on the tricuspid valve. There was more than one tumour in the other six patients: four had two or more tumours in the left atrium and two had recurrence in both left and right atrium. Recurrence has usually been within four years of the first operation (19 out of 23), but in our first case more than 10 years elapsed before the first recurrence, and in another it was not detected until 14 years after the first tumour was removed. ${ }^{13}$

Table 2 Reported cases of recurrent myxoma

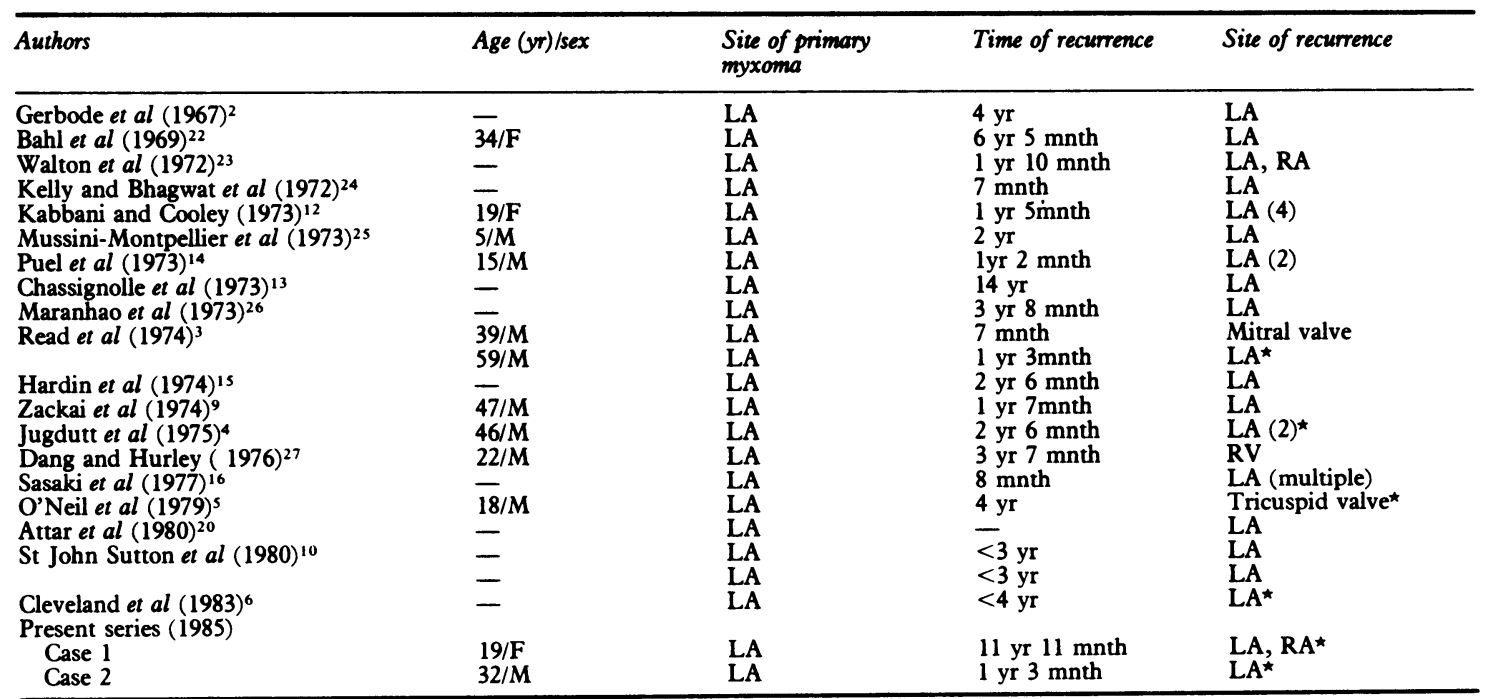

LA, left atrium; $R A$, right atrium; $R V$, right ventricle.

${ }^{\star}$ Cases having a second recurrence (Table 3 ). 
Table 3 Repeated recurrence of cardiac myxoma

\begin{tabular}{|c|c|c|c|c|c|c|}
\hline Author & $\begin{array}{l}\text { Sex/age (yr) at } \\
\text { first operation }\end{array}$ & $\begin{array}{l}\text { Site of original } \\
\text { myxoma }\end{array}$ & $\begin{array}{l}\text { Time to first } \\
\text { recurrence }\end{array}$ & $\begin{array}{l}\text { Site of first } \\
\text { recurrence }\end{array}$ & $\begin{array}{l}\text { Time to second } \\
\text { recurrence }\end{array}$ & $\begin{array}{l}\text { Site of second } \\
\text { recurrence }\end{array}$ \\
\hline $\begin{array}{l}\text { Read et al }(1974)^{3} \\
\text { Jugdutt et al }(1975)^{4} \\
\text { O'Neil et al }(1979)^{5} \\
\text { Cleveland et al }(1983)^{6} \\
\text { Present series }(1985)\end{array}$ & $\begin{array}{l}M / 59 \\
M / 46 \\
M / 18 \\
F / 48\end{array}$ & $\begin{array}{l}\text { LA } \\
\text { LA } \\
\text { LA } \\
\text { LA }\end{array}$ & $\begin{array}{l}1 \mathrm{yr} 3 \mathrm{mnth} \\
2 \mathrm{yr} 6 \mathrm{mnth} \\
4 \mathrm{yr} \\
<4 \mathrm{yr}\end{array}$ & $\begin{array}{l}\text { LA } \\
\text { LA (2) } \\
\text { Tricuspid valve } \\
\text { LA }\end{array}$ & $\begin{array}{l}7 \text { mnth } \\
3 \text { yr } 6 \text { mnth } \\
4 \text { yr } \\
<4 \text { yr }\end{array}$ & $\begin{array}{l}\text { LA (2) } \\
\text { LA (6), RA } \\
\text { RA } \\
\text { LA (multiple) }\end{array}$ \\
\hline Case 1 & $\mathbf{F} / 19$ & LA & $11 \mathrm{yr} 11 \mathrm{mnth}$ & LA, RA & $10 \mathrm{yr} 10 \mathrm{mnth}$ & $\begin{array}{l}R V \text {, tricuspid } \\
\text { valve, } L A\end{array}$ \\
\hline Case 2 & M/32 & LA & 1 yr 3 mnth & LA & 4 yr 5 mnth & $\begin{array}{c}\text { LA, RV, PA, } \\
\text { RA (3) }\end{array}$ \\
\hline
\end{tabular}

LA, left atrium; RA, right atrium; RV, right ventricle; PA, pulmonary artery.

Four of the six patients in whom myxoma recurred for a second time were men (Table 3). The time that elapsed between the first and second recurrence was less than five years in five of the six, the time in the sixth (our case 1) being nearly 11 years. The six cases of a second recurrence of myxoma indicate that it is likely. to occur in about $25 \%$ of patients in whom a first recurrence has taken place. There was more than one tumour at the second recurrence in five of the six, more than one chamber being involved in three of them.

Incomplete removal of a myxoma at the first operation might explain a few of the recurrences, especially when the operation had to be carried out hurriedly under hypothermia as in our first patient. Most of the recurrences, however, have followed more leisurely procedures using cardiopulmonary bypass, with wide excision of the atrial septum around the point of origin of the tumour. Recurrences have also occurred at a different site, even in a different cardiac chamber, from the first myxoma. One of the recurring tumours in each of the present cases actually arose from endothelium covering a Teflon patch in the atrial septum. Read et al suggested that implantation of tumour tissue from the primary myxoma might be responsible for some recurrences. ${ }^{3}$ This could happen either at operation or from damage to a large myxoma forced into the orifice of the mitral valve during atrial systole. This could explain only recurrences that were in the wall of the left atrium or in the mitral valve.

It is also possible that the recurrent tumours are quite distinct from the original myxoma and are the result of multiple foci of neoplastic change. The several reports of simultaneous development of more than one cardiac myxoma favour this hypothesis. Nichols and Hennigar describe postmortem findings in a young woman who had one large and five small myxomas in the left atrium and another small myxoma in the right atrium. ${ }^{28}$ All these seven myxomas had separate origins on the atrial septum. Other cases of multiple cardiac myxomas were reported by Frankenfeld $e t a l$ and Zajtchuk et al. ${ }^{29} 30$ There may also be a genetic factor in the multiple incidence of myxoma. Siltanen et al reported a patient who underwent surgery for myxomas that had developed simultaneously in both atria. ${ }^{31}$ Three of her seven children also developed atrial myxoma. Our first patient with two recurrences of myxoma also had a familial incidence of the condition.

Although myxoma is generally regarded as a benign tumour, there are reports of tumour emboli of myxoma that have behaved in a malignant fashion. A patient reported by Read et al had a secondary growth on the sternum some years after a left atrial myxoma was removed: a biopsy specimen was reported as showing myxosarcoma. ${ }^{3}$ In the case reported by Heath and Mackinnon there were multiple myxomatous infarcts in the lungs from a right atrial myxoma. ${ }^{32}$ In some of these embolic lesions myxomatous tissue had invaded the media of the pulmonary arteries. Similar invasion of the wall of the cerebral arteries in myxomatous cerebral embolism was reported by New et al. ${ }^{7}$ The histology of myxomas recurring in the heart has not usually suggested malignant change, nor has the histology of tumours which have recurred seemed in any way different from non-recurring myxoma. In only one case (Cleveland $e t a l$ ), where myxoma recurred twice in the left atrium, was there progression of the histological appearance from benign to malignant. ${ }^{6}$

Weighing up the four possible causes of recurrence-incomplete removal, seeding of tumour, multiple foci of tumour development, and malignant change-we believe that multiple foci of tumour growth best explain the condition in most cases. A few cases might recur because of incomplete removal of the primary tumour, but this cannot possibly explain all the features of the recurring myxomas we have described. Malignant change has been recognised in the tumour histology in only one of the reported cases. The association of multiple tumours with a familial incidence of myxoma is an interesting feature, and the difference in the sex incidence of primary and recurring myxomas is an aspect which remains unexplained.

We thank Dr J W Black, who carried out careful histological studies of the surgical specimens from our 
two patients, and Miss E M Edward of the Sir John Black Library for her assistance.

\section{References}

1 Crafoord C. Mitral stenosis and mitral insufficiency. In: Lam CR, ed. International symposizm on cardiovascular surgery. Henry Ford Hospital, Detroit, Michigan. Philadelphia: W B Saunders, 1955: 203.

2 Gerbode F, Kerth WJ, Hill JD. Surgical managment of tumors of the heart. Surgery 1967; 61: 94-101.

3 Read RC, White HJ, Murphy ML, Williams D, Sunn $\mathrm{CN}$, Flanagan WH. The malignant potentiality of left atrial myxoma. F Thorac Cardiovasc Surg 1974; 68: 85768.

4 Jugdutt BI, Rossall RE, Sterns LP. An unusual case of recurrent left atrial myxoma. Can Med Assoc $\mathcal{F}$ 1975; 112: 1099-1100.

5 O'Neil MB Jr, Grehl TM, Hurley EJ. Cardial myxomas: a clinical diagnostic challenge. Am $\mathcal{f}$ Surg 1979; 138: 68-76.

6 Cleveland DC, Westaby S, Karp RB. Treatment of intra-atrial cardiac tumors. $\mathcal{F} A M A$ 1983; 249: 2799-802.

7 New PFJ, Price DL, Carter B. Cerebral angiography in cardiac myxoma. Radiology 1970; 96: 335-45.

8 Burton C, Johnston J. Multiple cerebral aneurysms and cardiac myxoma. $N$ Engl f Med 1970; 282: 35-6.

9 Zackai AH, Weber DJ, Ramsby G, Wong B. Recurrence of left atrial myxoma. $\mathcal{F}$ Cardiovasc Surg (Torino) 1974; 15: 467-71.

10 St John Sutton MG, Mercier L-A, Giuliani ER, Lie JT. Atrial myxomas. A review of clinical experience in $\mathbf{4 0}$ patients. Mayo Clin Proc 1980; 55: 371-6.

11 Croxson RS, Jewitt D, Bentall HH, Cleland WP, Kristinsson A, Goodwin JF. Long-term follow-up of atrial myxoma. Br Heart $\mathcal{f}$ 1972; 34: 1018-23.

12 Kabbani SS, Cooley DA. Atrial myxoma. Surgical considerations. F Thorac Cardiovasc Surg 1973; 65: 731-7.

13 Chassignolle J-F, Termet H, Age C, et al. A propos d'une sèrie de 10 myxomes intracardiaques opérés. Annales de Chirurgie Thoracique et Cardio-Vasculaire 1973; 12: 297-8.

14 Puel P, Castany P, Enjalbert A. Notre expèrience de la chirurgie des myxomes intracardiaques. Annales de Chirurgie Thoracique et Cardio-Vasculaire 1973; 12: 2934.

15 Hardin NJ, Wilson JM, Gray GF, Gay WA Jr. Experience with primary tumors of the heart. Clinical and pathological study of 17 cases. Fohns Hopkins Medical fournal 1974; 134: 141-55.
16 Sasaki S, TsoLin Y, Redington JV, Mendez AM, Zubiate $\mathrm{P}, \mathrm{Kay} \mathrm{JH}$. Primary intracavitary cardiac tumors: a review of 11 surgical cases. $f$ Cardiovasc Surg (Torino) 1977; 18: 15-21.

17 Donahoo JS, Weiss JL, Gardner TJ, Fortuin NJ, Brawley RK. Current managment of atrial myxoma with emphasis on a new diagnostic technique. Ann Surg 1979; 189: 763-8.

18 Bulkley BH, Hutchins GM. Atrial myxomas: a fifty year review. Am Heart f 1979; 97: 639-43.

19 Richardson JV, Brandt B, Doty DB, Ehrenhaft JL. Surgical treatment of atrial myxomas: early and late results of 11 operations and review of the literature. Ann Thorac Surg 1979; 28: 354-8.

20 Attar S, Lee Y-C, Singleton R, Scherlis L, David R, McLaughlin JS. Cardiac myxoma. Ann Thorac Surg 1980; 29: 397-405.

21 Marvasti MA, Obeid AI, Potts JL, Parker FB. Approach in the management of atrial myxoma with long-term follow-up. Ann Thorac Surg 1984; 38: 53-8.

22 Bahl OP, Oliver GC, Ferguson TB, Schad N, Parker BM. Recurrent left atrial myxoma. Circulation 1969; 40: 673-6.

23 Walton JA Jr, Kahn DR, Willis PW III. Recurrence of a left atrial myxoma. Am $\mathcal{F}$ Cardiol 1972; 29: 872-6.

24 Kelly M, Bhagwat AG. Ultrastructural features of a recurrent endothelial myxoma of the left atrium. Archives of Pathology 1972; 93: 219-26.

25 Mussini-Montpellier J, Cornet E, Gillot F, Le Bodic M-F, Michaud J-L, Nomballais M-F. Aspects histologiques d'une recidive de myxome de l'oreilette gauche chez un enfant. Annales de Chirurgie Thoracique et CardioVasculaire 1973; 12: 239-40.

26 Maranhao V, Gooch AS, Yang SS, Goldberg $H$. Regrowth of a left atrial myxoma. Chest 1973; 63: 98100.

27 Dang CR, Hurley EJ. Contralateral recurrent myxoma of the heart. Ann Thorac Surg 1976; 21: 59-62.

28 Nichols J, Hennigar G. A case of bilateral multicentric cardiac myxoma. Archives of Pathology 1959; 67: 24-9.

29 Frankenfeld $\mathrm{RH}$, Waters $\mathrm{CH}$, Steiner RC. Bilateral myxomas of the heart. Ann Intern Med 1960; 53: 827-38.

30 Zajtchuk R, Fitterer JD, Strevey TE, Nelson WP. Bilateral atrial myxomas. Pre-operative diagnosis and successful removal. F Thorac Cardiovasc Surg 1975; 69: 291-4.

31 Siltanen P, Tuuteri L, Norio R, Tala P, Ahrenberg P, Halonen PI. Atrial myxoma in a family. Am $\mathcal{f}$ Cardiol 1976; 38: 252-6.

32 Heath D, Mackinnon J. Pulmonary hypertension due to myxoma of the right atrium. Am Heart 7 1964; 68: 22735 . 